\title{
Short communication: Detection of mastication speed during rumination in cattle using 3-axis, neck-mounted accelerometers and fast Fourier transfer algorithm
}

\author{
T. Tamura, ${ }^{1,2}$ (1) Y. Chida, ${ }^{3}$ and K. Okada ${ }^{1,4 *}$ (]) \\ ${ }^{1}$ United Graduate School of Veterinary Sciences, Gifu University, Gifu 501-1193, Japan \\ ${ }^{2}$ Iwate Agricultural Mutual Aid Association, Morioka 020-0857, Japan \\ ${ }^{3}$ Bycen Co. Ltd., Kobe 651-2275, Japan \\ ${ }^{4}$ Cooperate Department of Veterinary Medicine, Iwate University, Morioka 020-8550, Japan
}

\section{ABSTRACT}

There have been limited reports on mastication speed during cattle rumination. The objective of this study was to establish a method to detect mastication speed based on data obtained during rumination through the use of a 3-axis accelerometer attached to the neck. A 3 -axis accelerometer was attached to 6 dry Holstein cattle. When rumination behavior was observed, the accelerometer and the high-speed camera simultaneously recorded acceleration at the neck and moving image of the head movement. Based on the number of mastication movements recorded on video, mastication speed A was calculated. Data obtained from the 3-axis accelerometer were analyzed with fast Fourier transfer algorithm and identified as mastication speed B. The vibration of the neck recorded in the accelerometer during rumination was considered as mastication movement. Using Bland-Altman plot analysis, the mean difference between mastication speed $\mathrm{A}$ and mastication speed B was $0.041 \mathrm{~s} /$ bite, and the $95 \%$ limits of agreement ranged from -0.080 to 0.161 . Since mastication movement occurred periodically, it was possible to detect the movement using spectrum analysis, as mastication speed B. Although there were some differences between calculated speeds and speeds obtained from spectrum analysis, there was clinical compatibility between mastication speed A and B. This study showed the feasibility of establishing a detection method for mastication speed during rumination, which might provide a basic procedure for studying the purpose of mastication and the variable factors involved.

Key words: 3-axis accelerometer, cattle, mastication speed, rumination, spectrum analysis

Received September 19, 2019.

Accepted March 24, 2020.

*Corresponding author: keiji@iwate-u.ac.jp

\section{Short Communication}

Rumination is the process by which cattle regurgitate previously ingested feed stored in the rumen, masticate it further, and swallow it again (Herdt, 1997). Rumination is thought to make digesta into small particles and to enhance digestion (Kennedy, 1985; Herdt, 1997; Beauchemin, 2018). Subclinical diseases, health problems, DMI, and diet components are reported to affect rumination behavior (Soriani et al., 2012). Monitoring of rumination behavior might provide important information in management of cattle (Beauchemin, 2018).

The majority of studies on rumination monitoring have used observations of rumination time at long intervals (from several hours to 1 d; Bristow and Holmes, 2007; DeVries et al., 2009; Soriani et al., 2012). Those methods have fewer practical applications in the field because they require longer to detect abnormalities. Although the number is scarce, other studies focused on the repetitive pattern of mastication during rumination by measuring the time required for one bite (i.e., mastication speed).

Dado and Allen (1994) reported the mastication speed using a pressure transducer attached to a halter. They reported mastication speed during rumination was $0.93 \mathrm{~s} /$ bite for primiparous cows and $0.97 \mathrm{~s} / \mathrm{bite}$ for multiparous cows. Tani et al. (2013) reported mastication speeds of 0.90 to $1.13 \mathrm{~s} /$ bite using acoustic monitoring combined with a single-axis acceleration sensor. Matsui and Okubo (1991) measured mastication speed as 0.60 to $0.80 \mathrm{~s} /$ bite using a transducer attached to a halter, requiring the halters to be mounted with a special device that was not easy to attach or manage.

Doukoshi et al. (2014) detected a peak of $1.3 \mathrm{~Hz}$ (i.e., $0.77 \mathrm{~s} /$ bite) during rumination from the spectrum analysis of data obtained from pressure sensors attached to the necks of cows. However, this report did not include data on the speed of mastication. Matsui and Okubo (1991) pointed out the importance of mastication speed for evaluation of rumination behavior. However, 
the meaning of mastication speed during rumination has remained unclear. To further discuss the meaning and usefulness of mastication speed during rumination, development of easier techniques for measurement and compilation of data are required.

Recently it became clear that rumination behavior can be studied using a 3-axis accelerometer, which can be easily attached to the necks of cattle (Tamura et al., 2019). Behavior such as eating, rumination, and lying can be classified with high accuracy by analyzing the data recorded in the neck-mounted 3-axis accelerometer. With this technique, we can expect to calculate mastication speed based on data easily obtained from the 3 -axis accelerometer. To achieve this, a computing process is required for generating mastication speed from the acceleration data.

Rumination is assumed to involve periodic repetitive movements with almost constant rhythm. Therefore, we expect to obtain periodic wave from the 3-axis accelerometer attached to the neck. A spectrum analysis which can detect frequencies of waveforms is useful for time course data analysis of periodic changes. Fast Fourier transfer (FFT) is the representative algorithm used for this analysis (Brigham and Morrow, 1967). Therefore, analysis of acceleration data during rumination with FFT algorithm might allow us to obtain the main frequency, mastication speed.

The objective of this study was to obtain mastication speed using the measurement of acceleration at the neck during rumination and analysis with FFT, and to use a high-speed camera simultaneously to verify if the mastication speed calculated with this method is highly correlated with the actual mastication speed.

Six Holstein cattle in their dry period (mean age 3.8 yr \pm 0.9 ; mean \pm standard deviation) were part of this study. Each cow was kept inside their individual pen with a rubber mat and fed a diet shown in Table 1 twice per day at 0800 and $1700 \mathrm{~h}$ with free access to water. Before this study, all cattle were acclimated to a similar diet (Table 1) for more than $8 \mathrm{~d}$. The cattle in this study were all determined to be clinically healthy throughout the acclimation period and study.

The accelerometer Q'z TAG research (QTG-01, Sumitomo Electric Industries Ltd., Osaka, Japan) was used. The size was $41 \mathrm{~mm} \times 41 \mathrm{~mm} \times 14.5 \mathrm{~mm}$ (height $\times$ width $\times$ depth) and weighed 15 g. The detection accuracy of acceleration was 12 bits. The sampling frequency during the measurement was $20 \mathrm{~Hz}$, and the detection range of acceleration was set to $\pm 19.613 \mathrm{~m} /$ $\mathrm{s}^{2}$. As reported previously by Tamura et al., 2019, the accelerometer was placed inside a reinforced plastic case measuring $4.2 \mathrm{~cm} \times 9.0 \mathrm{~cm} \times 14.0 \mathrm{~cm}$ (Pelican Products, Inc., Torrance, CA). The case was then attached to the collar of the cows (collars were approximately $120 \mathrm{~cm}$

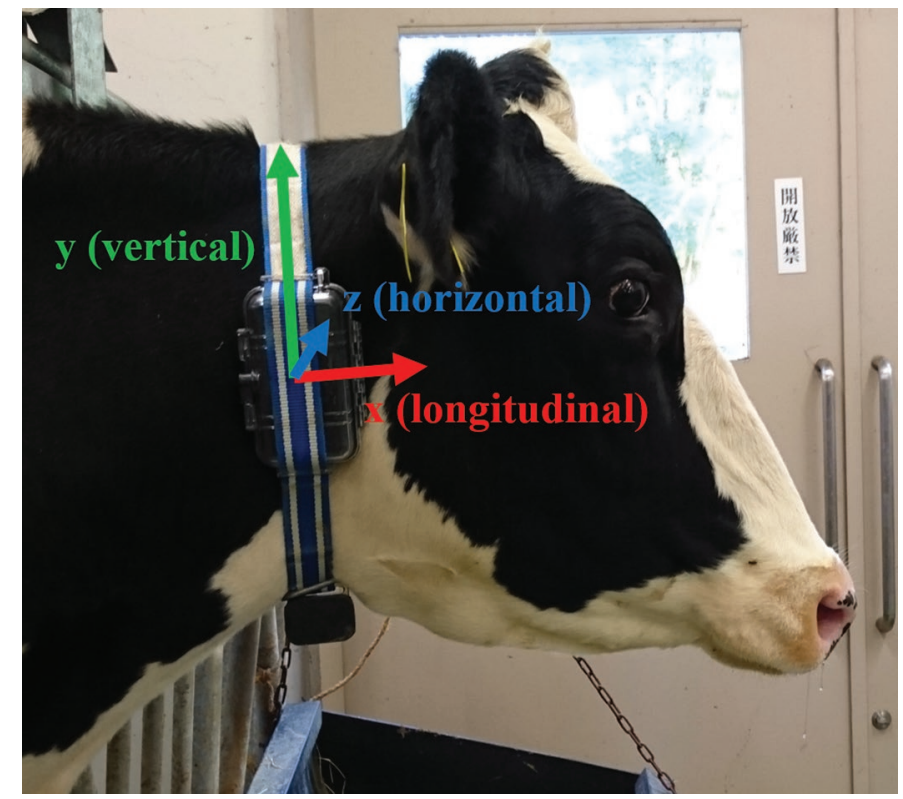

Figure 1. Cow with collar and 3-axis accelerometer.

long $\times 4 \mathrm{~cm}$ wide $)$ with weight on ventral $(600 \mathrm{~g})$. Each collar was adjusted to achieve a tight fit on the neck of each cow, and the acceleration devices to always be placed on the right side (Figure 1). Data were recorded for movements in 3 directions: longitudinal ( $\mathrm{x}$ : back and forth), vertical (y: up and down), and horizontal (z: left and right). Acceleration data were transmitted in real time to a computer through Bluetooth communication.

The DFK33UP1300 camera (The Imaging Source, Bremen, Germany) was fixed on a tripod and positioned to record head movement of the cow. The camera was connected to a computer with a USB cable, synchronized with acceleration data, and recorded at a sampling frequency of $20 \mathrm{~Hz}$. A high-speed camera-acceleration sensor synchronized recording. Display system software

Table 1. Feed composition (DM basis)

\begin{tabular}{lc}
\hline Item & Value \\
\hline Feed ingredients (kg/d) & \\
Timothy hay & 4.0 \\
Lucerne hay & 2.0 \\
Italian ryegrass straw & 4.0 \\
Beet pulp & 3.0 \\
Flaked corn & 1.0 \\
Chemical composition (\% of DM) & \\
DM (\%) & 87.6 \\
TDN & 62.0 \\
CP & 8.8 \\
ADF & 31.9 \\
NDF & 55.0 \\
NFC & 31.9 \\
\hline
\end{tabular}


(QTGS-C1, Sumitomo Electric Industries, Ltd., Osaka, Japan) was used as recording software.

After the morning feeding, each cow had an accelerometer attached and was allowed to move freely. When rumination behavior was observed by direct observation, video recording with the high-speed camera began. At the same time, data from the accelerometer were also recorded. Data without artifacts for more than $60 \mathrm{~s}$ were used for later analysis. The time window for acceleration data and video was set at $51.2 \mathrm{~s}$ (1,024 data points) as 1 epoch unit, and the data within these time periods were used for analysis. The number of mastication movements within a given epoch were counted using the corresponding video recording. The duration of swallowing and regurgitation was measured by direct observation using the same video recording. Then, mastication speed A was calculated using the following equation:

\section{$51.2 \mathrm{~s}$ - time for swallowing and regurgitations/ number of mastication movements $=$ mastication speed A (s/bite).}

The numerical array of acceleration data was subjected to offset processing by subtracting the average value in the epoch for each of the 3 axes, and then noise was reduced by 10-argument moving average processing. Further, the FFT algorithm was conducted after multiplying with Hamming window factor (Oppenheim et al.,1999) to improve frequency resolution. To emphasize the peak frequency, the arithmetic mean was calculated for periodograms of $\mathrm{x}-, \mathrm{y}-$, and z-axes, and the final spectrum of the particular epoch was obtained. A similar peak was detected by comparing mastication speed $\mathrm{A}$, and the inverse number of that frequency $(\mathrm{Hz})$ was set as mastication speed B ( $\mathrm{s} /$ bite).

To verify the normal distribution of data sets for mastication speed A and mastication speed B, the Anderson-Darling test was used. Scatter plots were created using mastication speed $\mathrm{A}$ and mastication speed $\mathrm{B}$, and the correlation analysis was conducted. Pearson correlation coefficients and $P$-values were calculated, and correlations were determined to be significant at $P<0.05$. In addition, Bland-Altman plot (Giavarina, $2015)$ was created to verify the agreement between mastication speed A and mastication speed B. All analyses were conducted using MatLab R2017a (Mathworks, Natick, MA) and Microsoft Excel 2016 (Microsoft Corporation, Redmond, WA).

The number of epoch (data set), which had only recording of rumination behavior without artifact (e.g., sudden movement of the neck, head shaking), was 120 in total. Based on videos recorded with a high-speed camera, periodic strong movements of the mandible were observed at the time of rumination. In addition, slight vibrations from the posterior head to the dorsal neck were observed accompanying rumination. Further, when the mouth was opened and closed, obvious vibrations of the loose skin were detected from the mandible to dewlap via ventral neck (Figure 2). Almost all epoch recorded contained one swallowing/ regurgitation, where mastication movement stopped for about $4 \mathrm{~s}$. All acceleration waveforms were similar to the previous report (Tamura et al., 2019); all 3 axes showed almost homogeneous and regular acceleration with amplitudes of 1 to $2 \mathrm{~m} / \mathrm{s}^{2}$, and acceleration was decreased during swallowing/regurgitation (Figure 3). Calculated mastication speed A (mean $\pm \mathrm{SD}$, skewness, and kurtosis) was $0.942 \pm 0.071$ (s/bite), 0.458, and -0.039 , respectively.

Periodograms for $\mathrm{x}-, \mathrm{y}-$, and $\mathrm{z}$-axes derived from the FFT are shown in Figure 4. Although slight differences were observed among axes, the first peak was observed close to $1 \mathrm{~Hz}$, the second peak was about twice the frequency of the first one and stronger for all axes. In addition, obscure peaks were detected at about 3-, 4-, and 5-fold higher frequencies than the first peak. To increase the sensitivity of detection, the arithmetic mean was calculated for periodograms from 3 axes (Figure 5). Reverse numbers of the first peak (mean $\pm \mathrm{SD}$, skewness, and kurtosis) were $0.901 \pm 0.071$ (s/

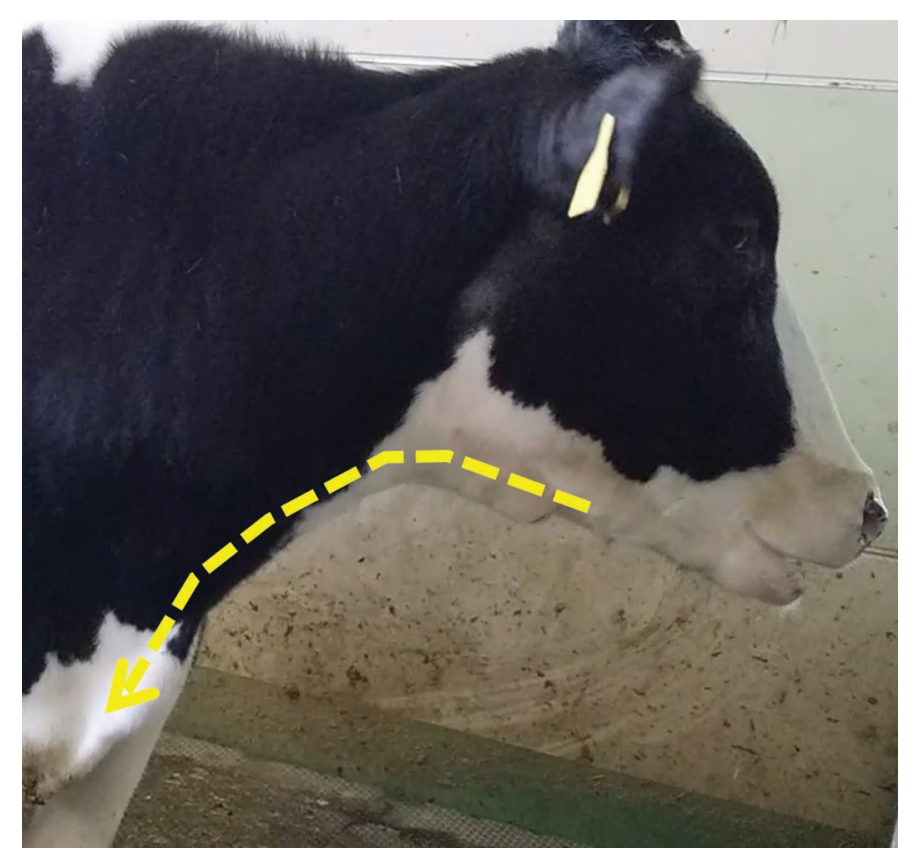

Figure 2. During rumination, skin vibration was observed from the mandible to dewlap via ventral neck (indicated by arrow). 

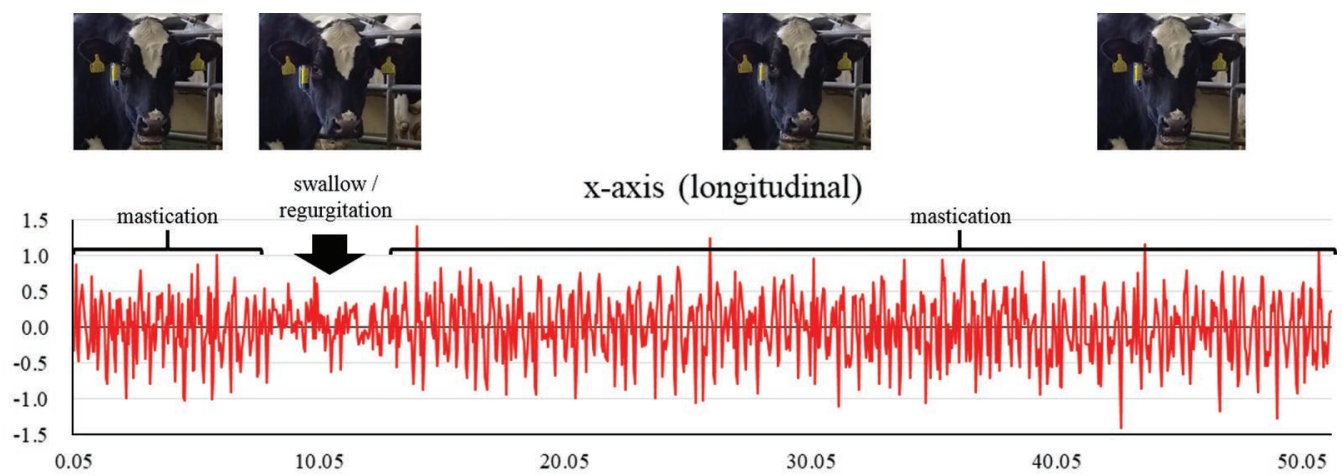

y-axis (vertical)

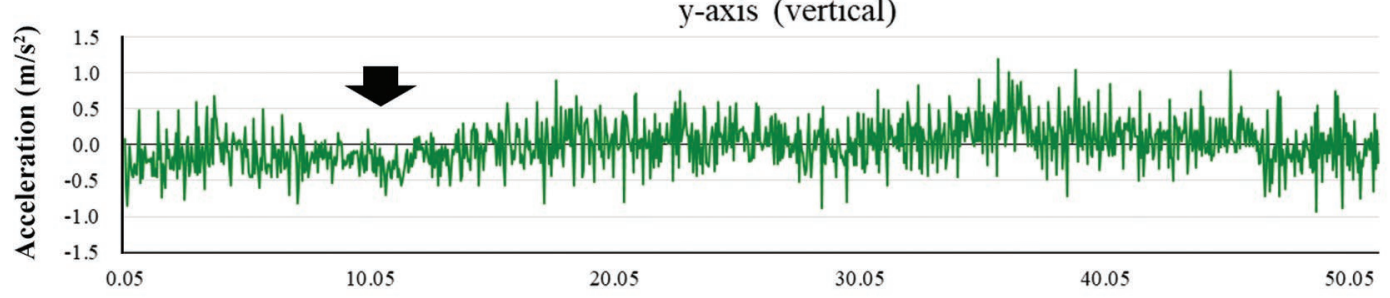

Z-axis (horizontal)

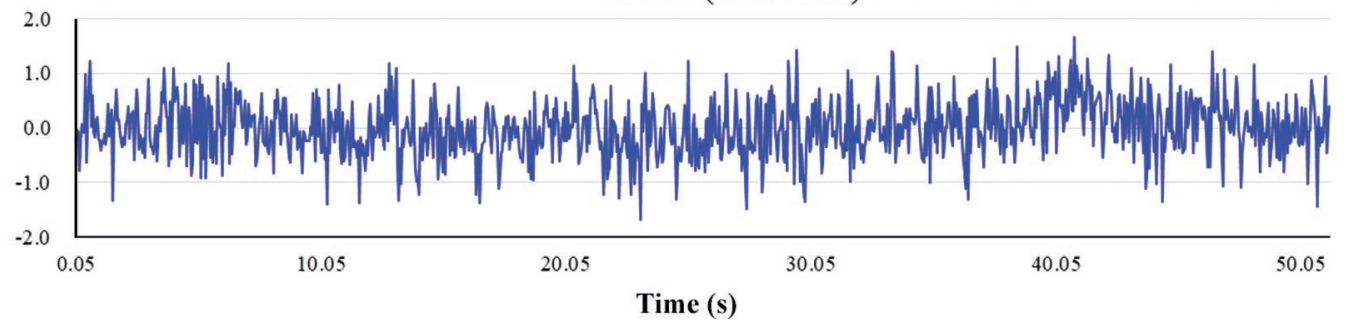

Figure 3. Acceleration waveforms observed during rumination (51.2 s) in longitudinal (top waveform), vertical (middle waveform), and horizontal directions (bottom waveform). They were detected with constant amplitudes of 1 to $2 \mathrm{~m} / \mathrm{s}^{2}$ in all 3 directions. During swallowing and regurgitation, acceleration rate decreased (indicated by arrows).

bite), 0.208 , and 0.153 , respectively. For those of the second peak were $0.456 \pm 0.033$ (s/bite), -0.188 , and -0.446 , respectively. Therefore, we set the peak close to mastication speed A as the first peak, and the reverse number of the first peak as the mastication speed B ( $\mathrm{s}$ / bite).

An Anderson-Darling test showed $P=0.138$ for mastication speed $\mathrm{A}$ and $P=0.337$ for mastication speed B. A scatter plot with mastication speed A and B is shown in Figure 6. Correlation was detected with a correlation coefficient of 0.625 , and $P<0.01$.

Furthermore, the agreement between mastication speed A and mastication speed B was verified using Bland-Altman plot (Figure 7). Table 2 shows the statistical analysis of Bland-Altman plots. The mean difference was $0.041 \mathrm{~s} /$ bite, suggesting the presence of a fixed bias where mastication speed A was slightly higher. The limits of agreement obtained from the samples ranged from -0.080 to $0.161 \mathrm{~s} / \mathrm{bite}$. Although no significant correlation was observed in the Bland-
Altman plots, the error tended to increase when the mastication speed exceeded $0.9 \mathrm{~s} /$ bite. Among total number of measurements, $96.7 \%$ had less than $\pm 20 \%$ of relative errors (Critchley and Critchley, 1999).

This study showed that mastication speed could be detected by analysis with FFT using acceleration data obtained from the 3-axis accelerometer attached to the necks of cattle. This indicates that mastication movement during rumination is periodic, and it can be detected at the neck.

Bungo et al. (1999) observed the movements of the jaw during rumination in detail. They reported that mastication movements during rumination are the repetitions of horizontal movements of the mandible as well as dispersion of the cud within the oral cavity by opening the mouth, followed by grinding of the cud with movements of the mandible in the reverse orientation. This means that the 2 main movements of "opening mouth" and "closing mouth" are included within one mastication movement during rumination. In the 

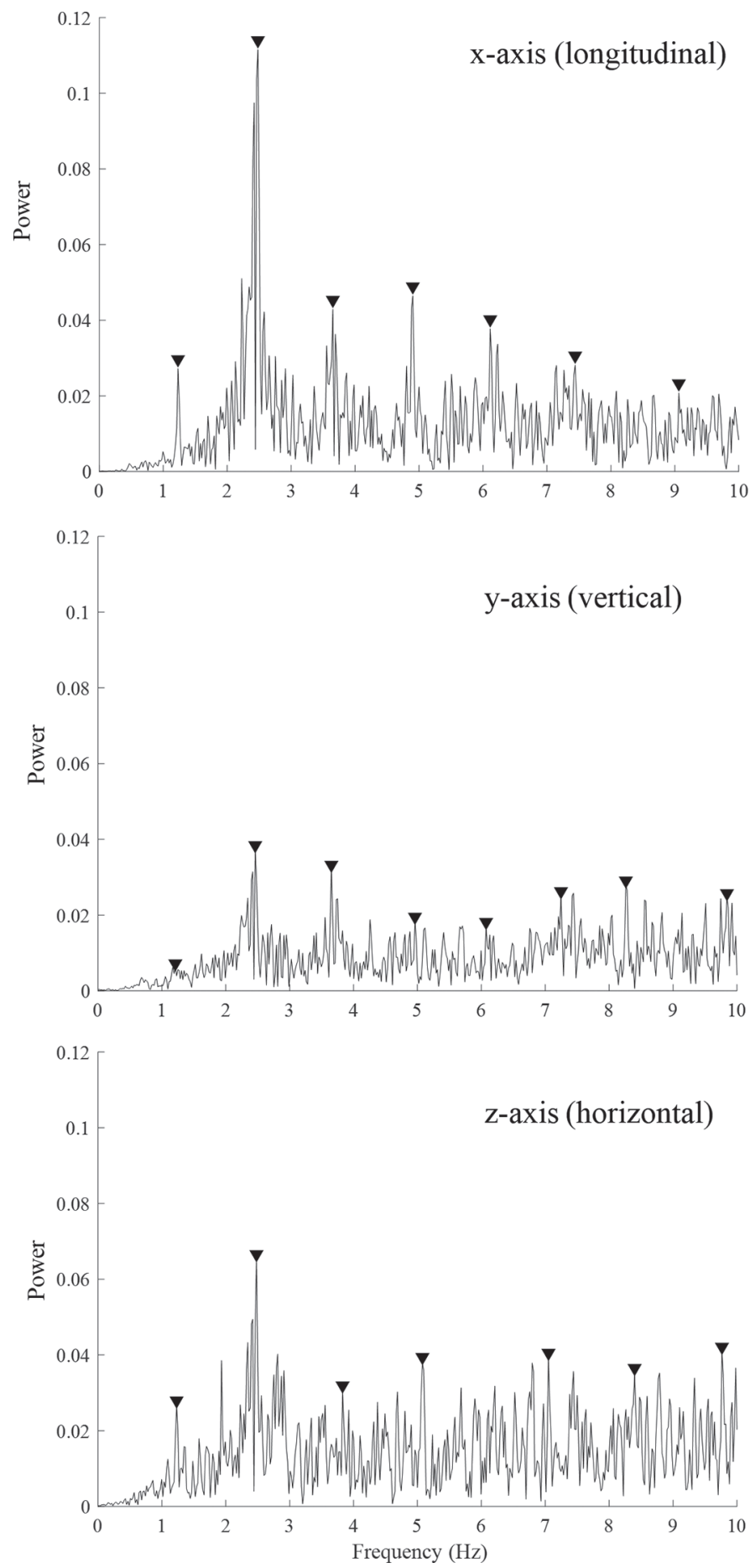

Figure 4. Periodograms obtained by fast Fourier transfer analysis of each of the 3 axes (example). The first peak occurs at around 1 $\mathrm{Hz}$, the second peak is about twice the frequency of the first one, and indistinct peaks at around 3,4 , and 5 times the frequency of the first peak were detected (arrow heads).

current study using the FFT analysis, a particularly obvious first peak and second peak were detected. The first peak was the frequency associated with the one mastication, and the second peak was almost double the frequency of the first peak. This suggested that the second peak showed movements of "opening" and "closing" mouth. In addition, visible neck skin vibration was observed in each phase of opening and closing, which was transmitted to the sensor, and was thought to be involved in the expression of a clear second peak. Doukoshi et al. (2014) measured rumination movements using a high-sensitivity low-frequency pressure sensor attached to the neck. When spectrum analysis was conducted, obvious peaks were observed at $1.3 \mathrm{~Hz}$ and $2.6 \mathrm{~Hz}$, which they described as characteristic peak frequencies observed during rumination. These were similar to our current study. Therefore, we believed that we could detect periodic movements during rumination clearly using the 3 -axis accelerometer attached to the neck in this study.

Muscles associated with mastication include the masseter, the lateral pterygoid, the medial pterygoid, and temporal muscles (Liebich et al., 2014). However, these muscles are not present at the location where the accelerometer was attached. Therefore, mastication movement during rumination is transmitted from the head to the neck as vibration, resulting in detection by the accelerometer. The results of the FFT show peaks in all of the x-, y-, and z-axes. Smith and Savage (1959) indicate that in herbivore masticatory movements, the masseter, medial pterygoid, and temporal muscles cooperate to produce a rotational movement of the lower jaw. Therefore, it suggests that vibrations due to the rotational movement of the lower jaw accompanying masticatory movement during rumination were transmitted to the neck, while being dispersed into 3 axes. In addition, obscure peaks observed after the second peak were considered the result of transmission and resonance (overtone) of vibrations emanating from the loose skin of the neck associated with rumination. However, in the high frequency region, peaks tended to become unclear due to attenuation and increased noises. Since peaks in the high frequency region were not considered to reflect individual movements, they were thought to be not important in the frequency analysis of cervical acceleration during rumination.

Results of correlation analysis showed significant correlation between mastication speed $\mathrm{A}$ and mastication speed B. Analysis of Bland-Altman plots showed fixed error and limit of agreement (about $0.24 \mathrm{~s} / \mathrm{bite}$ ). The fixed error suggested that the values of mastication speed A were slightly higher than of mastication speed $\mathrm{B}$. Although chewing movement during rumination was periodical, it was not rigorous. Occasionally the interval between chewing movements were slightly extended, thus the chewing count was reduced. This might have caused a higher mastication speed for A than the actual 


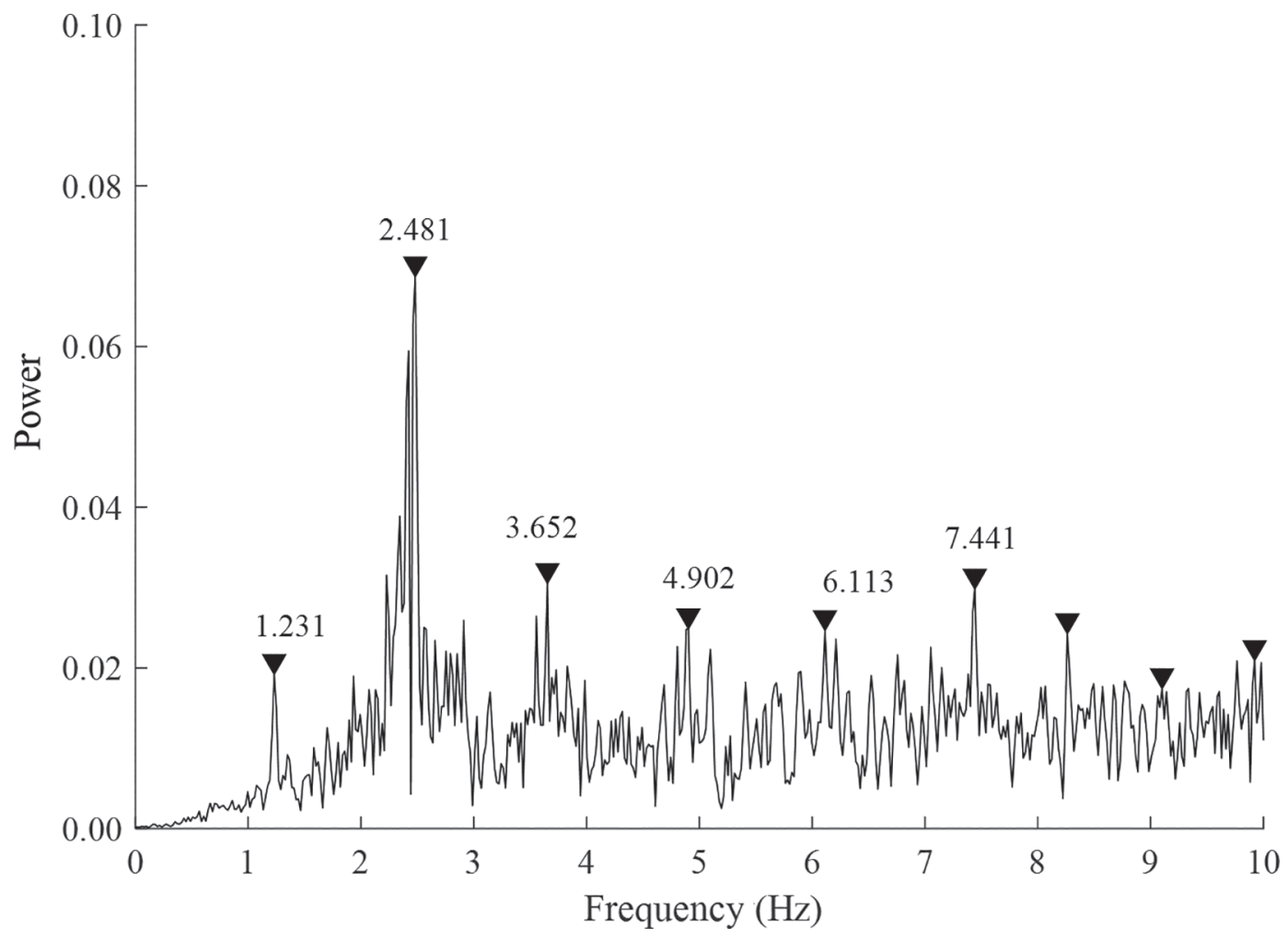

Figure 5. Periodogram obtained by calculating arithmetic mean of fast Fourier transfer analysis for the 3 axes (example). Arrow heads indicate detected peak and frequency.

speed. In addition, when the mastication speed went up, the error between the 2 methods tended to increase. When the mastication speed was high (slow mastication), irregular movement of chewing might have been included. However, mastication speed B, which can be directly calculated (not via counting) from the

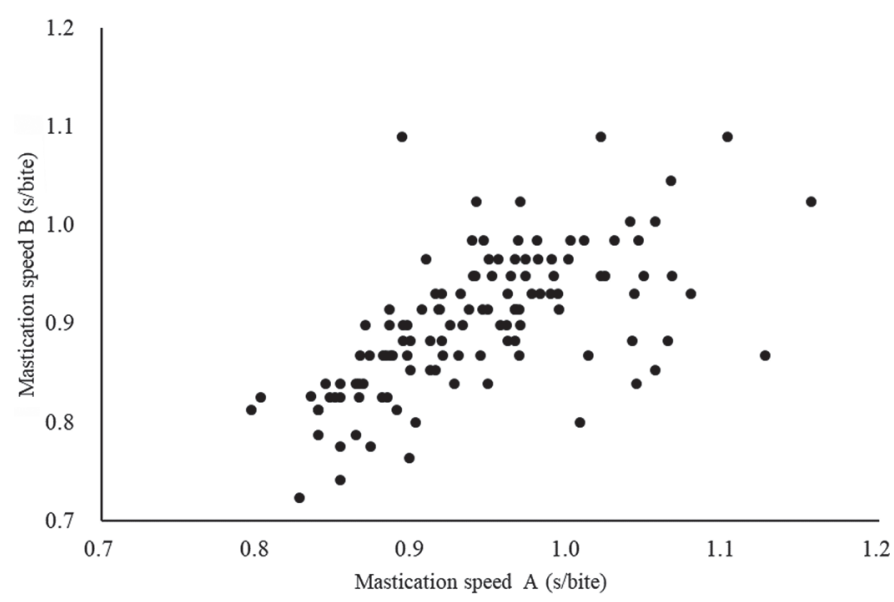

Figure 6. Scatter plot of mastication speed A and mastication speed B. Correlation coefficient $=0.625, P<0.01$. frequencies of repetitive movement and obtained from spectrum analysis, can approximate the real value of the mastication speed. Moreover, we applied one of the standards for compatibility proposed by Critchley and Critchley (1999). Clinical judgement can confirm the compatibility between mastication speeds A and B.

In this study, mean mastication speed calculated from FFT was $0.901 \mathrm{~s} /$ bite, which was within the range of 0.60 to $1.13 \mathrm{~s} /$ bite previously reported. However, the range of these values was more than $0.5 \mathrm{~s} / \mathrm{bite}$. These variations might be reflecting some other factors. A report using a low-frequency pressure sensor and spectral analysis (Doukoshi et al., 2014) suggested that there were individual differences in the spectrum during rumination (equivalent to mastication speed). No other reports mentioned variations due to environmental or animal factors. Although feeding and management, in addition to individual cattle condition, might cause variations of mastication speed, it was difficult to find the trends from previous research (Matsui and Okubo, 1991; Dado and Allen, 1994; Tani et al., 2013; Doukoshi et al., 2014) because of diversity in age, feed, and management styles.

In contrast, there has been much research done on rumination time. The amount of physically effective 
Table 2. Statistical analysis of Bland-Altman plots

\begin{tabular}{|c|c|c|c|c|}
\hline Variable & Value & SE & Confidence & $\begin{array}{l}\text { Confidence } \\
\text { interval }\end{array}$ \\
\hline $\begin{array}{l}\text { Mean difference } \\
\text { Standard deviation (SD) }\end{array}$ & $\begin{array}{l}0.041 \\
0.062\end{array}$ & 0.006 & 0.045 & -0.004 to 0.085 \\
\hline Mean - 1.96 SD & -0.080 & 0.010 & 0.039 & -0.100 to -0.061 \\
\hline Mean + 1.96 SD & 0.161 & 0.010 & 0.039 & 0.142 to 0.181 \\
\hline Correlation coefficient & $\begin{array}{c}-0.005 \\
(P=0.957)\end{array}$ & & & \\
\hline
\end{tabular}

NDF in feeds (Yang and Beauchemin 2006), forage particle size (Zebeli et al., 2007), percentage of roughage in TMR (Maekawa et al., 2002a), amount of concentrated feed (Okamoto, 2000), blood cortisol level (Bristow and Holmes, 2007), inflammatory diseases and liver function (Calamari et al., 2014), rumen acidosis (DeVries et al., 2009), subclinical ketosis (Kaufman et al., 2016), milk yield (Kaufman et al., 2018), parity (Maekawa et al., 2002b), and heat stress (Abeni and Galli, 2017) can affect rumination time. It is obvious that individual condition, feeding, and management can alter rumination behavior. These factors can also affect mastication speed during rumination. Further studies are needed to clarify this. The mastication speed detection method used in this study was completed in a shorter time than the measurement of rumination time. If the fluctua- tion factors of mastication speed are clarified, real-time evaluation of rumination behavior will be possible.

This study established a detection method for mastication speed during rumination using a 3 -axis accelerometer attached to the neck. This may become the basic procedure to understand the meaning and variation factors of mastication speed during rumination.

\section{ACKNOWLEDGMENTS}

This work was supported by Livestock Promotional Subsidy from the Japan Racing Association (Tokyo, Japan). The authors have no conflicts of interest directly relevant to the content of this article. The sponsor had no control over the interpretation, writing, or publication of this study.

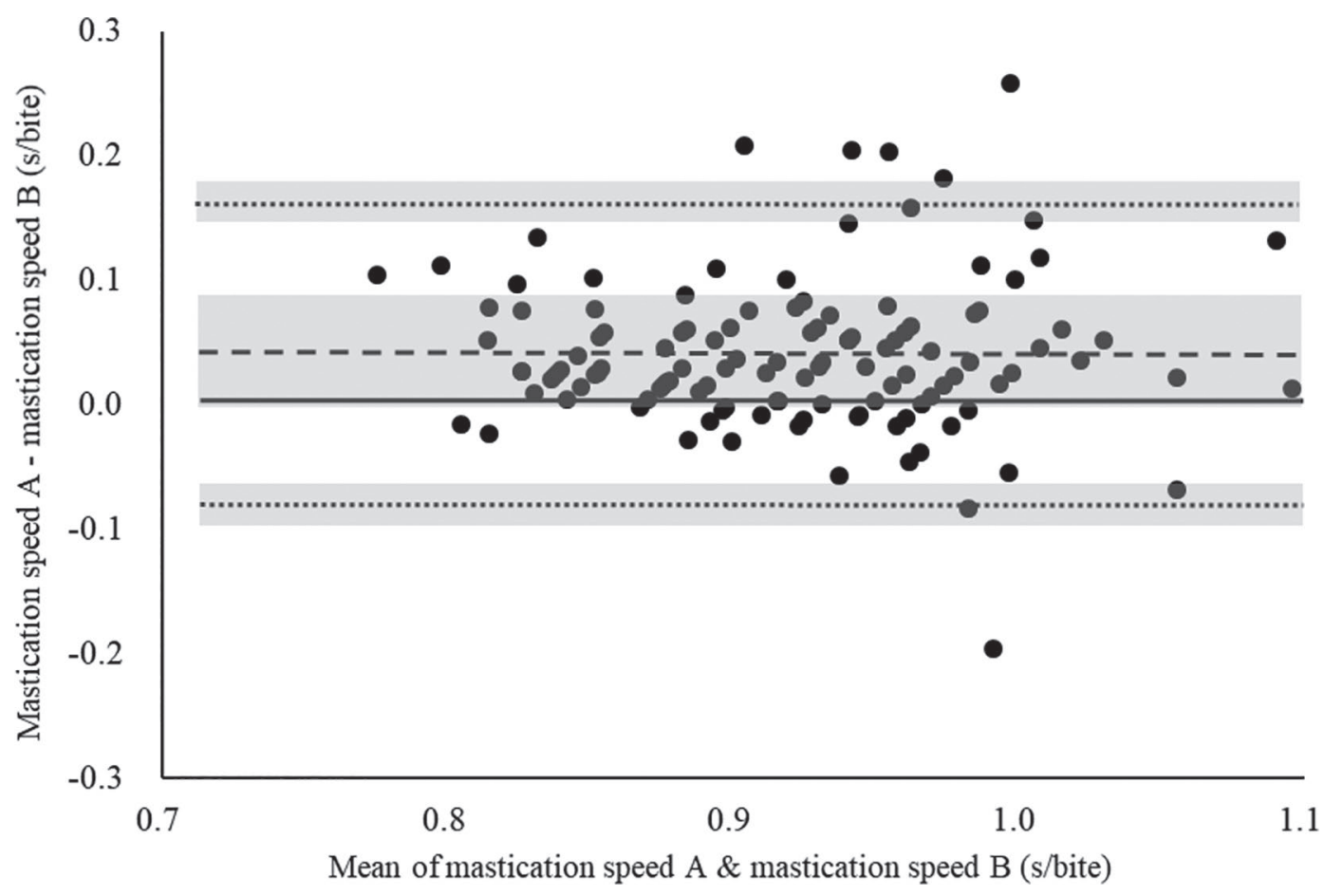

Figure 7. Bland-Altman plots for comparison between mastication speed A and mastication speed B. Dashed line denotes bias (mean of difference) and dotted lines denote $95 \%$ limits of agreement (1.96 SD of difference). Shaded areas represent $95 \%$ confidence interval limits for mean and limits of agreement. 


\section{REFERENCES}

Abeni, F., and A. Galli. 2017. Monitoring cow activity and rumination time for an early detection of heat stress in dairy cow. Int. J. Biometeorol. 61:417-425. https://doi.org/10.1007/s00484-016-1222-z.

Beauchemin, K. A. 2018. Current perspectives on eating and rumination activity in dairy cows. J. Dairy Sci. 101:4762-4784. https:// doi.org/10.3168/jds.2017-13706.

Brigham, E. O., and R. E. Morrow. 1967. The fast Fourier transform. IEEE Spectr. 4:63-70. https://doi.org/10.1109/MSPEC.1967 .5217220 .

Bristow, D. J., and D. S. Holmes. 2007. Cortisol levels and anxietyrelated behaviors in cattle. Physiol. Behav. 90:626-628. https://doi .org/10.1016/j.physbeh.2006.11.015.

Bungo, T., Y. Nakano, K. Okano, M. Hayashida, H. Kawagoe, H. Furusawa, K. Yasukochi, T. Matsuishi, K. Izumi, M. Shimojo, M. Furuse, and Y. Masuda. 1999. Direction of jaw movement in dairy cattle during the rumination period. Appl. Anim. Behav. Sci. 64:227-232. https://doi.org/10.1016/S0168-1591(99)00037-4.

Calamari, L., N. Soriani, G. Panella, F. Petrera, A. Minuti, and E. Trevisi. 2014. Rumination time around calving: An early signal to detect cows at greater risk of disease. J. Dairy Sci. 97:3635-3647. https://doi.org/10.3168/jds.2013-7709.

Critchley, L. A., and J. A. Critchley. 1999. A meta-analysis of studies using bias and precision statistics to compare cardiac output measurement techniques. J. Clin. Monit. Comput. 15:85-91. https: //doi.org/10.1023/A:1009982611386.

Dado, R. G., and M. S. Allen. 1994. Variation in and relationships among feeding, chewing, and drinking variables for lactating dairy cows. J. Dairy Sci. 77:132-144. https://doi.org/10.3168/jds.S0022 -0302(94)76936-8.

DeVries, T. J., K. A. Beauchemin, F. Dohme, and K. S. SchwartzkopfGenswein. 2009. Repeated ruminal acidosis challenges in lactating dairy cows at high and low risk for developing acidosis: Feeding, ruminating, and lying behavior. J. Dairy Sci. 92:5067-5078. https: //doi.org/10.3168/jds.2009-2102.

Doukoshi, A., T. Seo, and F. Kashiwamura. 2014. Development of an automatic monitoring system for ruminating activities of dairy cattle using a highly sensitive low-frequency pressure sensor. Nihon Chikusan Gakkaiho 85:163-169. https://doi.org/10.2508/ chikusan.85.163 [in Japanese with English abstract].

Giavarina, D. 2015. Understanding Bland Altman analysis. Biochem. Med. (Zagreb) 25:141-151. https://doi.org/10.11613/BM.2015 .015 .

Herdt, T. 1997. Digestion: The fermentative processes. Pages 331-359 in Textbook of Veterinary Physiology 2nd ed. J. G. Cunningham, ed. W. B. Saunders, Philadelphia, PA.

Kaufman, E. I., V. H. Asselstine, S. J. LeBlanc, T. F. Duffield, and T. J. DeVries. 2018. Association of rumination time and health status with milk yield and composition in early-lactation dairy cows. J. Dairy Sci. 101:462-471. https://doi.org/10.3168/jds.2017-12909.

Kaufman, E. I., S. J. LeBlanc, B. W. McBride, T. F. Duffield, and T. J. DeVries. 2016. Association of rumination time with subclinical ketosis in transition dairy cows. J. Dairy Sci. 99:5604-5618. https: //doi.org/10.3168/jds.2015-10509.

Kennedy, P. M. 1985. Effect of rumination on reduction of particle size of rumen digesta by cattle. Aust. J. Agric. 36:819-828. https://doi .org/10.1071/AR9850819.
Liebich, H. G., J. Maierl, and H. E. König. 2014. Muscles of the head. Pages 119-130 in Veterinary Anatomy of Domestic Mammals. 6th ed. H. E. König and H. G. Liebich, ed. Schattauer, Stuttgart, Germany.

Maekawa, M., K. A. Beauchemin, and D. A. Christensen. 2002a. Effect of concentrate level and feeding management on chewing activities, saliva production, and ruminal $\mathrm{pH}$ of lactating dairy cows. J. Dairy Sci. 85:1165-1175. https://doi.org/10.3168/jds.S0022 $-0302(02) 74179-9$

Maekawa, M., K. A. Beauchemin, and D. A. Christensen. 2002b. Chewing activity, saliva production, and ruminal $\mathrm{pH}$ of primiparous and multiparous lactating dairy cows. J. Dairy Sci. 85:11761182. https://doi.org/10.3168/jds.S0022-0302(02)74180-5.

Matsui, K., and T. Okubo. 1991. A method for quantification of jaw movements suitable for use on free-ranging cattle. Appl. Anim. Behav. Sci. 32:107-116. https://doi.org/10.1016/S0168 $-1591(05) 80035-8$.

Okamoto, M. 2000. Comparison of rumination activities of dairy herds fed relatively high and low concentrate diet. Anim. Sci. J. 71:5056. https://doi.org/10.2508/chikusan.71.50.

Oppenheim, A. V., R. W. Schafer, and J. R. Buck. 1999. Design of FIR filters by windowing. Pages 465-478 in Discrete-Time Signal Processing 2nd ed. Prentice Hall, Upper Saddle River, NJ.

Smith, J. M., and R. J. G. Savage. 1959. The mechanics of mammalian jaws. Sch. Sci. Rev. 141:289-301.

Soriani, N., E. Trevisi, and L. Calamari. 2012. Relationships between rumination time, metabolic conditions, and health status in dairy cows during the transition period. J. Anim. Sci. 90:4544-4554. https://doi.org/10.2527/jas.2011-5064.

Tamura, T., Y. Okubo, Y. Deguchi, S. Koshikawa, M. Takahashi, Y. Chida, and K. Okada. 2019. Dairy cattle behavior classifications based on decision tree learning using 3-axis neck-mounted accelerometers. Anim. Sci. J. 90:589-596. https://doi.org/10.1111/asj .13184

Tani, Y., Y. Yokota, M. Yayota, and S. Ohtani. 2013. Automatic recognition and classification of cattle chewing activity by an acoustic monitoring method with a single-axis acceleration sensor. Comput. Electron. Agric. 92:54-65. https://doi.org/10.1016/j.compag.2013 .01 .001 .

Yang, W. Z., and K. A. Beauchemin. 2006. Effects of physically effective fiver on chewing activity and ruminal $\mathrm{pH}$ of dairy cows fed diets based on barley silage. J. Dairy Sci. 89:217-228. https://doi .org/10.3168/jds.S0022-0302(06)72086-0.

Zebeli, Q., M. Tafaj, I. Weber, J. Dijkstra, H. Steingass, and W. Drochner. 2007. Effects of varying dietary forage particle size in two concentrate levels on chewing activity, ruminal mat characteristics, and passage in dairy cows. J. Dairy Sci. 90:1929-1942. https://doi . org $/ 10.3168 /$ jds.2006-354.

\section{ORCIDS}

T. Tamura ๑ https://orcid.org/0000-0001-8982-5719

K. Okada ๑ https://orcid.org/0000-0002-8831-6709 